\title{
Review of Enlightenment of Emotional Factors in Krashen's Affective Filter Hypothesis on English Teaching Research in College
}

\begin{abstract}
Zheng Yaoqing ${ }^{1}$
${ }^{1}$ School of Foreign Languages, Hangzhou Normal University Qianjiang College, Hangzhou, Zhejiang, 310018, China zhengyaoqing1122@163.com

ABSTRACT

Affective Filter Hypothesis describes the relationship between emotional factors and the process of second language acquisition, which is one of the five hypotheses of Krashen's Monitor Model. This review sorts out and analyses the status quo and teaching enlightenment of the three major emotional factors to the listening, speaking, reading, and writing in college English classes.
\end{abstract}

Keywords: emotional factors, Affective Filter Hypothesis, listening, speaking, reading, writing, college English teaching

\section{INTRODUCTION}

American linguist Krashen is the most influential and accomplished researcher in second language acquisition. In 1985, Krashen [1] proposed a complete model of second language acquisition through numerous practice and research, which is called Monitor Model. Its five core hypotheses are (1) the Acquisition-Learning Hypothesis; (2) the Monitor Hypothesis; (3) the Input Hypothesis; (4) The Natural Order Hypothesis; (5) The Affective Filter Hypothesis, in which the last hypothesis has attracted more and more attention and has been regarded as a key factor in second language acquisition.

The concept of affective filter was first proposed by Dulay and Burt [2] in 1977. It aims to explain how emotional factors affect the process of foreign language learning. They defined emotional filter as, "an internal processing system that subconsciously prevents learners from absorbing language based on factors called 'emotions' by psychologists." Later, Professor Krashen of the University of Southern California, incorporated and developed into the Affective Filter Hypothesis, which believes that the learner's acceptance of understandable language input, in the process of second language acquisition, is a necessary condition for acquisition, but it is not a sufficient condition and cannot be input from language alone. Considering the success of language learning, two explanations are usually applied for learner differences: one is the difference in the amount of comprehensible language input received by the learner; the other is the learner's emotional factor at work. The affective filter hypothesis is to illustrate the relationship between affective factors and the process of second language acquisition. In other words, affective factors play a role in filter input and vary from person to person--can hinder or accelerate language acquisition. Only under the best emotional conditions would real acquisition occur. Krashen divided emotional factors into three categories: anxiety, motivation, and selfconfidence, thereby three best emotional conditions include: the learner has a strong motivation to learn, full of confidence and in a good mood; there is nothing too high or low anxiety.

This essay consists of three parts. The first part will lay the emphasis on the how to apply the motivation factor to refine English teaching. Its heuristic propositions and suggestions will respectively include the application of three stages in listening classes and the change of teacher's role from controller to guide regarding to speaking teaching as well as combination with short-term and long-term motivation in respect of reading classes and cultivation of student's attention on corpus and teacher's encouragement from the perspective of writing. The second part will summarize the influence of self-confidence factor on English teaching, which indicates the cornerstone of successful listening teaching, the significance of indirect correction in oral English teaching, the key to enhance students' self-confidence in three stages and the help of Length 
Approach in writing classes. The last part will underscore the factors of causing language anxiety.

\section{THE ENLIGHTENMENT OF THE MOTIVATION FACTOR ON ENGLISH TEACHING}

Motivation is one of the most cardinal emotion factors. Krashen [3] (1982) pointed out that motivation can affect second language (L2) learners' grades, perseverance and classroom performance. Motivation in L2 acquisition refers to the desire and booster of learners to learn a foreign language. It is manifested and embodied in a strong thirst or even fondness as well as a conscious initiative and enthusiasm for knowledge in mastering a language (Dai Weidong, He Zhaoxiong, 2002). According to Gardner and Lambert (1972) [4], two main types of motivation can be categorized: One is instrumental motivation, that is, using language as an instrument to achieve a certain practical purpose, such as getting a well-paid occupation; the other is integrative motivation, that is, learners choose to learn a particular L2 because they are interested in the people and culture represented by the target-language group. While another more classic dimension is considered the motivation from the perspective of intrinsic and extrinsic sides (Atkinson, McClelland, Clark, Lowell, 1953) [5] : the former is to obtain pleasure and satisfaction from the language learning activity itself, while the latter regards a language as an approach to reach a certain goal. These two different criteria are prone to be link respectively, that is, integrative motivation is apt to associated with the intrinsic one, and at the same time, instrumental motivation is referable to the extrinsic one (Chambers, 1999) [6] . It can be clearly seen that motivation of English learning can be the internal factor for mastering this English language, which as well is a positive psychological state. Therefore, motivation contributes to the improvement of learning efficiency, while, on the contrary, once one lacks motivation for learning English, learning efficiency will be considerably reduced.

\subsection{Three Stages in Listening to Promote Motivation}

In the College English Syllabus (2017) [7], the Ministry of Education puts forward the five major language skills of listening, speaking, reading, writing, and translation for college English to discipline students, of which listening ranks first and is considered to be the most fundamental skill. In English learning, listening is an input item and an important way for students to learn this language. The ability to speak is largely based on listening comprehension.

A common phenomenon could be explicitly shown in the English learning of Chinese college students, that is, the vast majority of college students are forced to listen to English, which infers that they seldomly have any intention or interest in listening. Their purpose of learning English is simple: for non-English major college students, they listen to English just for passing College English Test Band 4 or College English Test Band 6; for English major college students, their aim is to qualify for Professional Level 4 and Professional Level 8. This kind of English learning model enables most of the students torture the experience of listening. Therefore, teachers are supposed to adopt diversified teaching methods in order to stimulate students' learning motivation, arouse their interest in listening and enhance the competence of listening practice. Traditional listening classes have emphasized practicing a plethora of listening training, which mostly tend to be repetitive question types so that it is not easy to arouse the enthusiasm of the students, thereby teachers can employ other methods, such as topic introduction, extensive listening, intensive listening, and film dubbing to make the question types diversified, including not only the main question types of the listening test with different difficulty levels, but also the design of interesting dubbing projects; they can also use games, Riddles, cartoons, music, jokes, or scene reappearance, these methods can help students get encouragement and fun, and at the same time help improve the fluency and smoothness of English, so that students can experience the joy of learning English.

British linguist Mary Underwood (1989) [8] proposed three steps in teaching based on related theories: pre-listening, while-listening, and postlistening. Therefore, when teachers are teaching listening, they can create a learning environment with low emotional filtering and high motivation for students from these three aspects. In the pre-listening stage, everything is supposed to be prepared in advance, and if it is not planned, it will be abolished. In order to have a good listening lesson, teachers must make full preparations in advance, otherwise the result will be half the result with half the effort. Creating an environment conducive to student learning is one of the important tasks of every teacher in the classroom. A good listening classroom atmosphere should be warm and active, equal and relaxed, so that students feel psychologically safe and free and learn something (Mai Hongyu, 2006) [9] . According to Krashen's hypothesis, emotional factors affect the comprehensible input of learners, so the listening materials should be preset on the basis of students' emotional psychology. Therefore, teachers should pay more attention to the selection of listening materials because whether the listening materials are interesting or not and the degree of difficulty would have a direct impact on students' emotional factors, thereby interesting and appropriately difficult listening materials (" $i+1$ ", that is, a state refer to a little more advanced than the current state of the learner's L2) are prone to help stimulate students' motivation and promote listening learning process. 
In the while-listening stage, due to the weak foundation, students are prone to slack in the listening class. The more they are motivated, the more they can't understand. Listening teaching was once in a dilemma. Krashen's "emotional filtering hypothesis" emphasizes the importance of emotional factors. Teachers should properly regulate students' motivation levels in listening teaching, effectively reduce students' slack, and follow the easy-to-difficult guidelines to cultivate students' selfconfidence. The task of listening teaching is to cultivate students' comprehension and communication skills, but listening comprehension is an internal activity of people's mental language, which is unobservable, so teachers must rely on various exercises to test their level (Li Xueqing, 2002) [10]. First, the four skills of listening, speaking, reading and writing are combined to promote listening by reading, listening by writing, and listening by speaking, so as to train students' communicative skills. Secondly, through operational output, such as filling in the blanks, judging right and wrong, etc., you can give feedback on your comprehension ability. Teachers explain listening strategies in class so that students can learn to process information on their own. If you encounter difficulties in the listening process, teachers should help solve them in time, try to eliminate the emotional factors of students' anxiety and panic, and create a learning atmosphere with low emotional filtering intensity for students.

In the post-listening stage, checking the answers by teachers and students does not mean the end of the listening teaching process. Teachers should first train students to learn to self-assess, review the original materials to understand what they understand or have not heard, and what listening strategies they have used, and sum up from it. Worth learning; the teacher analyzes the existing problems and deficiencies through the feedback of the students, and proposes improvement methods on this, so that the students can get a certain development and progress. According to Krashen's Affective Filter Hypothesis, the mistakes made by students should not be corrected or published immediately, but should be expressed in the form of encouragement to enhance students' motivation for listening.

\subsection{Teacher's Role from Controller to Guide regarding to Speaking Teaching}

At present, the majority of Chinese college students foster weak oral English competence and low learning motivation. It is mainly associated in three aspects about school, teachers and students themselves. For example, initially, some college provide students with fewer opportunities to communicate in English because of the time in class; secondly, the quality of teachers needs to be improved; finally and most fundamentally, few factors could be motivated students to absorb in speaking part by virtue of most domestic English tests involving no oral section.

Teachers must fully realize that the classroom should be student-oriented, that is, to recognize the student's dominant position, because the object of teaching is the thinking, brain, and emotional college students. Corder (1981) once said, "Effective language teaching should not go against the natural process but adapt to it; teaching should not hinder learning, but should help and promote learning, and should not allow students to adapt to teachers and teaching materials, while teachers and textbooks adapt to students." Therefore, first of all, teachers should avoid traditional classroom teaching controllers and classroom center roles in classroom teaching. Students should be allowed to play the main role in the classroom, and teachers should play the role of director. To guide students to fully enter the state of performance, every classroom activity is a performance, which can improve students' motivation to speak English; secondly, teachers should carefully select teaching materials and choose moderately difficult and interesting teaching materials Teachers should also carry out substantial classroom design and classroom activities, allowing students to choose their favorite topics for communication and practice, so as to conform to students' interests and hobbies, fully mobilize students' enthusiasm for language output, and let every student actively participate in classroom activities. Therefore, in the classroom, teachers do not act as evaluators, but allow students to evaluate each other. In this way, teachers only act as the guides of student activities, so that students can fully feel the freedom and equality in the classroom, enabling students to experience the active learning to traditional passive learning, which is conducive to students' spoken English output.

\subsection{Combination with Short-term and Long- term Motivation in Respect of Reading}

Reading teaching pours attention into students' motivation on vocabulary learning. Non-English majors have the following motivations for memorizing words. The first is to successfully pass the CET- 4 and CET- 6 or at least the CET-4. Most students are motivated to learn vocabulary for this reason; the second is the need to go abroad. Some students have to take IELTS and TOEFL; the third is that students love English since childhood and have a strong interest in learning; the fourth is to successfully pass mid-term and final exams and graduate successfully. For the first, second, and third students, the motivation for vocabulary learning is relatively strong, they can actively speak in class, take the initiative to participate in classroom teaching activities, and actively take various methods to memorize words after class; the fourth student is not motivated to remember vocabulary. Without the motivation to learn English, they think that 
as long as they review before the exam and then pass the exam, finally can they graduate. English majors will passively or actively absorb English words because they have a large number of English reading and general education classes, thereby improving their vocabulary.

Huge differences in the effect of vocabulary mastery would be occurred among students with different motivations. Therefore, teachers are prone to put the emphasis on improving the learning motivation of students in the fourth category and analyzing the reasons. Most of the students have poor English foundation to remember words, even if words are memorized, they can't use them correctly, and gradually lose their interest in learning English words. Thereby, teachers can guide such students to understand the importance of English learning in vocabulary and to start memorizing the most basic words as well as follow the Ebbinghaus's remembering rules and gradually expand their vocabulary through multiple channels, such as reading simple English stories, English magazines and newspapers, listening to English songs, watching English movies and develop short-term and long-term vocabulary memory plans. When students' short-term plans are realized, their sense of accomplishment will enhance their learning motivation in vocabulary.

For English majors, vocabulary is no longer a problem for them, but the learning habit of English reading is a long-term task that requires them to have a strong learning motivation. First of all, teachers should help students to uphold educational standards of combining long-term motivations with short-term one as well as maintaining a lasting enthusiasm for reading. For example, students' lofty ideals and future careers related to English are considered to be the long-term motivations, while passing an important test or achieving some small goals can be the short-term motivations. Both motives are indispensable, thereby teachers enable to draw on long-term motivation to stimulate students to insist on participating in daily reading training and develop good reading habits, while use short-term motivations to encourage students to complete specific reading tasks and gradually relish the time of reading. Over time, students would develop interest in reading and enhance motivation of reading. Secondly, teachers design scientific and vivid activities to spur the process of reading activities. The individual physiology, psychology and age of students as factors that affect the development of reading ability are directly related to the teacher's arrangement of activities in reading teaching. Only activities suitable for students' characteristics can stimulate students' learning motivation. With the increase of age, students' abstract ability increases, and they are in a period of high mood, which is also a period of sensitivity and consciousness, so that students can do well in explaining their opinions after reading articles. Teachers can arrange English seminars, speech contests, debates and other activities to stimulate students' ideological expression after reading and the enthusiasm of participating in discussions.

\subsection{Student's Attention on Corpus and Teacher's Encouragement from the Perspective of Writing}

It is best for teachers to choose corpus that is diverting, resonant and enthusiastic for students to recite, because these inputs are the most interpretable, prominent and repetitive for students to memory. For example, original soundtrack materials, English newspapers and magazines, and even advertisements and songs can stimulate interest in writing. Moreover, students are supposed to observe life in-depth, and then record glimpse in the form of observation notes in order to foster the capability in writing about daily life. The accumulation of articles is natural and brilliant. At the same time, the teacher's guidance and demonstration are also the basic guarantee for students to internalize corpus referred.

When learners write, various errors and mistakes would appear, such as substantive errors like spelling of words and grammar, as well as structural transfer such as the lack of meaning and ambiguity of words. These are the necessary processes for learners from the beginning of learning to the real acquisition of. Therefore, in the process of composition teaching, teachers should tolerate students' mistakes and mistakes and adopt active and effective methods to guide students to find problems. For example, through the mutual approval of writing group activities and teacher-student discussion among students, students should find errors in composition. And encourage them to correct themselves as much as possible. This will not only help find out the reason for their mistakes, but also understand their perceptions of the mistakes and use feedback strategies. Not only will it not hurt the students' self-esteem, but it will also allow them to find a way to correct the mistake A sense of accomplishment, that is, motivation. At the same time, students should be praised in time for their progress so that they can always maintain a strong interest and passion for learning. According to the above operations, students will be affirmed by teachers and classmates in the process of progress, and strengthen their motivation in the affirmation, and they will naturally become active independent learners.

\section{THE INFLUENCE OF SELF- CONFIDENCE FACTOR ON ENGLISH TEACHING}

Self-confidence is a positive affirmation of one's own ability and level as well as a unique self-judgment for uncertain factors that will happen. For L2 learners, selfconfidence is the caliber of foresight and control of the difficulties encountered in the process of L2 learning. 
Compared with the emotion of anxiety, self-assured L2 learners are prone to actively recognize and take action in accordance with the different hurdles and environment that will be encountered based on their existing language learning experience. At the same time, self-confidence is an essential prerequisite for L2 learners to succeed because those who with strong certitude are apt to own strong learning motivation, thereby they are not afraid of losing face in the process of language learning, and dare to show their learning brainchild proudly in the crowd as well as communicate in L2 with others. Even making mistakes will not affect them in which they can gain more knowledge from their mistakes and indulge themselves in future language learning, thus forming a series of positive chain reactions.

\subsection{The Bedrock--Effective Evaluation and Comfortable Learning Environment--of Listening Teaching}

Students who lack self-confidence in English learning are afraid of accepting learning tasks and cannot solve the problems encountered in the learning process. They dare not talk in English, dare not answer the questions raised by the teacher, dare not show themselves in English because they do not believe they can do it. Moreover, poor test scores can make the situation worse. Some students have begun to give up English learning and get by, which puts more pressure on their English learning. In college English listening classes, many students will not express their opinions because they are afraid of making mistakes, and teachers are eager to correct students' mistakes. Over time, teachers' frequent corrections would erode students' courage when facing the input of listening materials and also failed to achieve the expected learning effect. At the same time, passively accepting learning tasks will cause students to resist the class and even the English language, thereby the input in the college English listening class is prone to be invalid. In actual teaching practice, teachers tend to praise and affirm the students more and not rush to correct mistakes, so that students have sufficient self-confidence and sense of accomplishment and reduce the anxiety of language learning because effective classroom evaluation build the foundation of successful teaching. Under the encouragement of the teacher's positive language evaluation, a domino effect would set into motion, which students gain a sense of accomplishment and satisfaction, their anxiety disappears, their self-confidence is enhanced, and their interest in learning is greatly improved. They are then apt to actively participate in the classroom, gain more intelligible language input, and enhance language learning.

Also, taking into account the unstable emotional state of students and the inability to concentrate for a long time, humor is used in English listening and speaking classroom teaching to adjust the emotional state of students in a timely manner and bring physical and mental pleasure to students. It helps to create a more comfortable learning environment, enhances students' curiosity, and helps students relieve extreme anxiety and anxiety. Only when students feel comfortable, relaxed and confident, can they truly absorb the intelligible language input they receive, and make it smoothly reach the language acquisition mechanism of the brain, which is externalized into language skills.

\subsection{The Significance of Indirect Correction in Oral English Teaching}

Krashen believes that the self-confidence of learners lies at the heart of the individual's colloquial ability. Students who are more confident and likely to express themselves would learn faster because this kind of learner communication language get involved in more practical opportunities, which is an important condition for the progress of colloquial English learning. On the other hand, students with low self-confidence tend to be self-defeating, like always thinking that their communication abilities in English are inferior to others. This kind of students long to be appreciated by others, but they dare not get colloquial exercise by themselves, thus forming a negative cycle in their learning lives.

In foreign language learning, like the English language, confidence is mainly manifested in two aspects: students' confidence in teachers and students' self-confidence (the latter one is more significant). Selfconfidence is a necessary condition for completing English speaking tasks. However, freshmen and most college students lack sufficient self-confidence. During the practice, errors should be corrected, but if teachers often interrupt students' speaking, self-confidence would be frustrated, so that there is no sense of accomplishment in the learning process. The teacher should choose the way to correct the mistakes reasonably according to the focus of the classroom activities. Even if it is necessary to correct errors, teachers must pay attention to teaching methods and art; if students make obvious mistakes in communication, teachers should lag behind in correcting errors; never interrupt students in the communication process, thereby discouraging students' enthusiasm. Scientific error correction is an effective way to maintain students' self-confidence because students receive timely guidance and advice from teachers after oral communication activities, and further enhance their selfconfidence in learning. This is also a task that teachers must complete in cultivating students' oral communication skills. Several ways of scientific error correction could be applied, that is the indirect correction, such as comprehension check or request for clarification, rising intonation questions and also paraphrasing. 


\subsection{The Key to Enhance Students' Self- confidence in Three Stages}

English learning has been laid stress on the reading in college. In the process of improving English reading ability, it is necessary to stimulate students' learning motivation and learning initiative through the ways of emotional filter and then enhance students' selfconfidence in reading, which result in clarifying the purpose of reading as well as reducing students' pressure in reading. If the students improve on their own, then the mood would turn into relaxed and delighted, thereby the ability to understand and absorb English articles would naturally foster and augment. On the contrary, the students' English reading scores and capability would improve slowly and inefficiently.

The improvement of students' English reading ability could effectively profit from emotional control. Firstly, before conducting a large amount of English reading training, teachers are supposed to exercise emotional control on college students. Teachers act as instructors to patiently guide every learner, instill reading methods and techniques, and cultivate their interest in reading. Secondly, it is necessary for students to choose reading materials that are suitable for the difficulty levels, which tend to be i+1 (involved in the above 2.1), that is, the input English language materials should not be too difficult or easy, because only choosing materials of suitable difficulty notches can be better galvanize students' learning motivation and also enhance their selfconfidence. In addition, controlling the emotions of English learners after reading is supposed to be concerned. In order to continue to stimulate their enthusiasm for English reading, the teaching instructor can give learners some pertinent, encouraging, and stimulating comments and evaluations, so that they probably gain a sense of accomplishment and then increase their confidence, which would be substantially conducive to English learning.

\subsection{The Length Approach-Minimizing the Impact of Emotional Filters}

College students' comprehensive English competence is embedded in writing, which is a quiet signal strand of English teaching in order to exercise students' logical thinking and analyze problem-solving ability, intensely students' reading volume, and expand humanistic vision. Therefore, writing teaching, as an organic component of university English teaching, cannot be left stranded in the traditional deductive teaching stage, nor can it separate the teaching process from the writing process. The most important thing is that it cannot ignore the emotional factors of learners because positive emotions in the entire writing teaching is apt to bolster students' zest in English writing and polish up students' autonomous learning awareness as well as promote students' writing ability and comprehensive language ability.

College teachers, in the writing class, incline to fully consider the emotional factors of students, so as to minimize the influence of them. The Length Approach proposed by Professor Wang Chuming (2000) [11] focuses on the major role of emotional factors in the input and output stages of writing. It starts from the perspective of improving self-confidence in English language learning and enlighten students to write long compositions through handpicked writing tasks, which favors establishment and enhancement students' confidence in learning English and encourages students to promote their English language application skills. The design of the teaching task in The Length Approach pours great attention into the emotions and experience of students. The core concept of this teaching is studentoriented-- in other words the teaching principle in writing is at the heart of the interaction between teachers and students, which fundamentally and functionally solves English language learning in emotional problems. The characteristics of this approach could be summarized in three aspects: first, writing is selected as a breakthrough in four parts (listening, speaking, reading, and writing) of English language learning, which puts the emphasis on writing to learn. Second, a brand-new evaluation system is established to evaluate the quality and quantity. In this standard, quantity is selected first because quantity of English writing promotes quality. Third, reward from teachers and peers, in the evaluation, is selected as the mainstream. The application of this approach overcomes students' emotional barriers, strengthens students' sense of accomplishment and selfconfidence, speed up the transformation of acceptable knowledge into expressive knowledge, and enable students to surpass themselves and fully tap their potential.

\section{THE IMPLICATION OF ANXIETY FACTOR ON ENGLISH TEACHING}

Anxiety usually manifests as self-doubt, restlessness, tension and other negative emotions, while language anxiety mainly refers to the fear or anxiety that a learner has when he needs to use a foreign language or a second language for expression. Horwitz and Cope (1986) defined foreign language anxiety (FLA) as "a distinct complex construct of self-perceptions, beliefs, feelings, and behaviors related to classroom language learning arising from the uniqueness of language learning process", and further pointed out that FLA includes communication anxiety, test anxiety and negative evaluation anxiety.

Among three emotional, the language anxiety is a complex psychological phenomenon unique to language 
learning, which many of researchers have a relatively consistent view on this (Gardner, 1985; Steinberg \& Horwitz, 1986; Young, 1992; Aida, 1994). A large amount of research results has indicated that most anxiety is connected with students' listening comprehension and oral output; FLA is negatively correlated with foreign language performance and teachers' assessment of student achievement (Horwitz, 1986; MacIntyre \& Gardner, 1989, 1991; Young, 1992; Aida, 1994; Liu Runqing, Wen Qiufang, 1993), but other scholar (Eysenck, 1989) believes that anxiety is positively related to foreign language learning performance; early research on anxiety (Scovel, 1978) believes that there is no linear relationship between anxiety and foreign language learning performance. Therefore, several confusions about the impact of language anxiety on foreign language learning performance has been still at issue (MacIntyre \& Gardner, 1991; Young, 1992; Horwitz, 2001).

Reasons for anxiety from college English learners includes many-sided aspects: competition can cause anxiety because when they compare themselves with their peers who successfully cultivate the English language, they may feel anxiety and stress; classroom activities or teaching methods may also be causation of FLA; language tests can also lead to the same negative effect. It is worth noting that anxiety and confidence are related to each other: when the degree of anxiety is lower, the level of confidence will be stronger; there is a mutual cyclic relationship, thereby, producing real and meaningful falls in anxiety foster the rise in confidence. Therefore, the consideration of learning leverage of this emotional element can refer to the third point.

\section{CONCLUSION}

Through the above review, I subscribe the view that several deficiencies are existed in the research between Affective Filter Hypothesis and second language teaching: one difficulty is that the ambiguous relationship between self-confidence and learning has occurred--whether the former affecting the latter or the latter influencing the former, which worth discussing; the other problem is that teachers how to manage a moderate degree of anxiety during teaching because the degree of anxiety is invisible and has individual differences, which brings about teachers feeling anxiety not being accurate.

\section{REFERENCES}

[1] Krashen, S.D., Language Acquisition and Language Education, Alemany Press, 1985.

[2] Dulay, H., Burt, M., Remarks on Creativity in Language Acquisition. In M. Burt, H. Dulay \& M. Finnochiaro (Eds.), Viewpoints on English as a Second Language (pp. 95-126). New York: Regents Press, 1977.
[3] Krashen, S.D., Principles and practice in second language acquisition, New York: Pergamon Press, 1982.

[4] Gardner, R. C., \& Lambert, W. E. d., Attitudes and motivation in second language learning, Rowley, MA: Newbury House Publishers, 1972.

[5] Mcclelland, D. C., Atkinson, J. W., Clark, R. A., \& Lowell, E. L., The Achievement Motive, East Norwalk Appleton-Century-Crofts, 1953.

[6] Chambers, G. N., Motivating Language Learners, Clevedon: Multilingual Matters Lud., 1999.

[7] Higher Education Department of Education Ministry, College English Syllabus, Beijing: Tsinghua University Press, 2017.

[8] Underwood, Teaching Listening, New York: Longman Inc, 1989.

[9] Hongyu Mai, The Impact of Affective Factors on the Teaching of English Listening in Colleges, Journal of Guilin Normal College. 2006, 20(4):114-117. DOI: $10.3969 /$ j.issn.1001-7070.2006.04.029.

[10] Xueqing Li, ANALYSIS OF KRASHEN'S AFFECTIVE FILTRATION HYPOTHESIS AND TEACHING OF LISTENING COMPREHENSION, Journal of China West Normal University (Philosophy \& Social Sciences). 2002, 0(3):102-105. DOI: 10.3969/j.issn.16729684.2002.03.023.

[11] Chuming wang, Ruiying Niu, Xiaoxiang Zheng, Foreign Language Teaching and Research, 2000.

[12] Horwitz, E. K., Horwitz, M. B., Joann Cope, Foreign Language Classroom Anxiety, The Modern Language Journal. 1986. 70(2), 125-132. DOI: https://doi.org/10.1111/j.15404781.1986.tb05256.x.

[13] He Li, A Tentative Study of the Function of the Affective Strategy and Its Application in Foreign Language Teaching, Journal of Jilin Huaqiao University of Foreign Languages, 2007.

[14] Li Xiaoning, On the Effects of Krashen's The Affective Filter Hypothesis in English Listening Learning, The Guide of Science \& Education. 2013. 0(14): 81-82. DOI: 10.16400/j.cnki.kjdkz.2013.05.031.

[15] Zhengzheng Chen, "Affective Filter Hypothesis" and emotional factors in college English teaching, Journal of Jiamusi Vocational Institute. 2013, (02). 